\title{
Force Analysis for Concrete Hyperbolic Arch Dam of Songbaishan Reservoir
}

\author{
Ji Dongyu \\ Hunan Urban Construction College \\ Xiangtan, China \\ hnjdy@126.com
}

\author{
Zhuang Xiaorui \\ Yellow river henan bereau \\ Zhengzhou, China \\ 11665580@sina.com
}

\begin{abstract}
Arch dam is a water retaining arch structure that convex upstream on the plane, the stability of arch dam does not need to rely on its own weight in water to maintain, mainly using the reaction of the bedrock of arch side to support and the section of arch ring mainly bear the axial reaction force, which can take good advantage of the strength of the dam material. Therefore, arch dam is a good dam type, whose economy and security are very good. The paper uses the finite element method to analysis the force of concrete hyperbolic arch dam of Songbaishan reservoir and gives the dam stress and deformation distribution regularities in the course of construction and operation. The research results show that the stress and deformation values are small and it can meet the design requirements. The structure is safe and reliable. The research provides a certain reference for the design and construction of concrete hyperbolic arch dam structure.
\end{abstract}

Keywords-Songbaishan reservoir; Hyperbolic arch dam; Force analysis; Stress distribution; Deformation analysis.

\section{PROJECT PROFILE}

Songbaishan reservoir is located in nanming river, which is the tributary of qingshui river, in Guiyang City , Guizhou Province. The distance is $29 \mathrm{~km}$ from the damsite to Guiyang[1]. The control catchment area toward upstream is $127 \mathrm{~km}^{2}$. The project is a water conservancy projects, which is predominantly irrigation and combined with power generation and water delivery[2]. The normal pool level of reservoir is $43.89 \mathrm{~m}$; the design flood level is $47 \mathrm{~m}$ and the corresponding level of tail water is $9 \mathrm{~m}$; the check flood level is $48 \mathrm{~m}$ and the corresponding level of tail water is $11 \mathrm{~m}$. The pivotal project consists of the dam, bottom outlet, diversion tunnel, diversion-type hydropower station and other buildings[3]. The dam was concrete hyperbolic arch and the maximum height of the dam is $52.5 \mathrm{~m}$ and the thickness of dam base is $8.65 \mathrm{~m}$. The ration of thickness and height of arch dam section is 0.18 and the maximum central angle is $122^{\circ} 32^{\prime}$ and the minimum central angle is $73^{\circ} 38^{\prime}$. The strength grade of concrete is C20[4].

\section{Calculation Model}

\section{A. Model Parameters.}

The strength grade of concrete of the hyperbolic arch dam of Songbaishan reservoir is C20, whose elastic modulus is $25.5 \mathrm{GPa}[5]$, Poisson's ratiois 0.167 , volumeweight is $24 \mathrm{kN} / \mathrm{m}^{3}$. The rock stratum of damsite is limestone, whose elastic modulus is 19GPa, Poisson's ratio is $0.28[6]$.

\section{B. Model Element.}

The structure models of concrete arch dam and bedrock use 8-node isoparametric block element. The element is applied to the three-dimensional entity structure, which has some characters such as plasticity, creep, swelling, stress stiffening, large deformation and large strain. The element has 8 nodes, which has three translational degrees of freedom[7].

\section{Model Dimension.}

The size of the entire computing model[8]: the longitudinal length is $200 \mathrm{~m}$, the transverse length is $250 \mathrm{~m}$, the vertical length is $160 \mathrm{~m}$, the proposed scope of the model: $200 \mathrm{~m} \times 250 \mathrm{~m} \times 160 \mathrm{~m}$ (the longitudinal length of the river $x$ the transverse length $\times$ the length of the vertical length). The element division of arch dam and rock are shown in Fig.1.

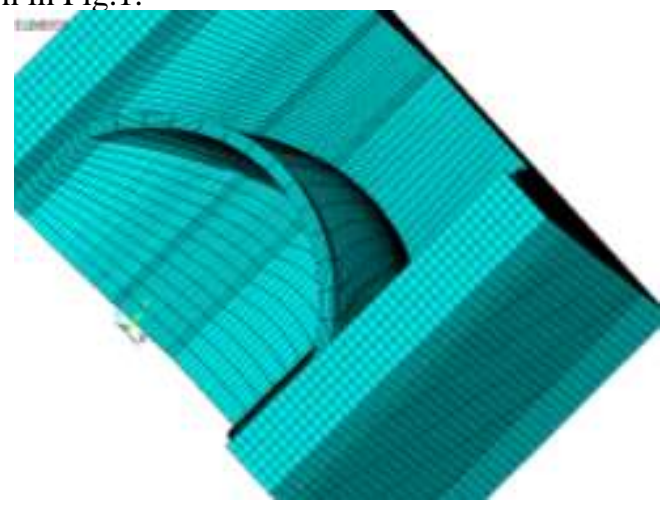

Figure 1. Element division of arch and rock

\section{The Calculation Working Case.}

Considering the force characters of arch dam during the course of construction and operation, the paper considers the following 5 working conditions[9]: case 1: structural weight; case 2: structural weight, normal water level and tailwater level; case 3: structural weight, design flood level and tailwater level; case 4: structural weight, check flood level and tailwater level; case 5: structural weight, design flood level, tailwater level and earthquake.

\section{ARCH STRUCTURE ANALYSIS}

\section{A Stress Analysis.}

By the finite element analysis of concrete hyperbolic arch dam of Songbaishan reservoir, the paper gets the figures of the first principal stress and the vertical stress of arch dam, which are shown in Fig.2 to Fig.11. 


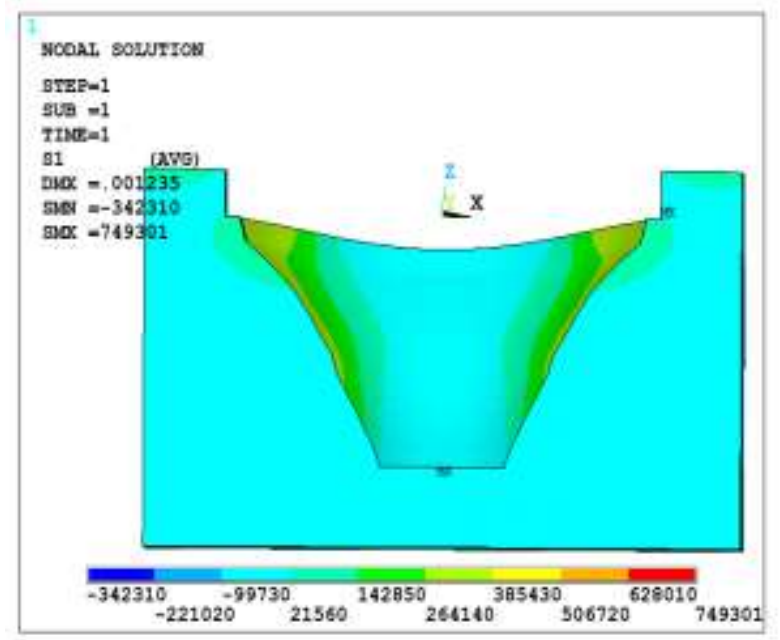

Figure 2. The first principal stress cloud map of arch dam under case $1(\mathrm{~Pa})$

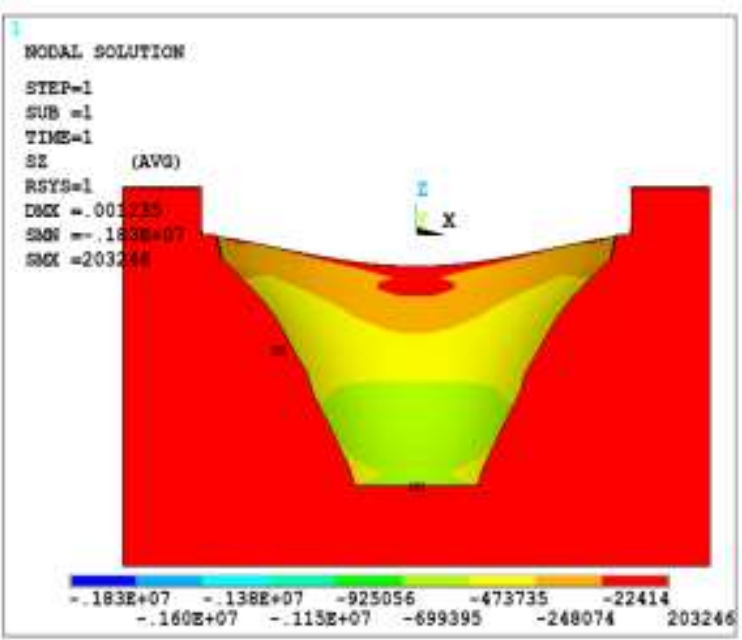

Figure 3. The vertical stress cloud map of arch dam under case 1（Pa

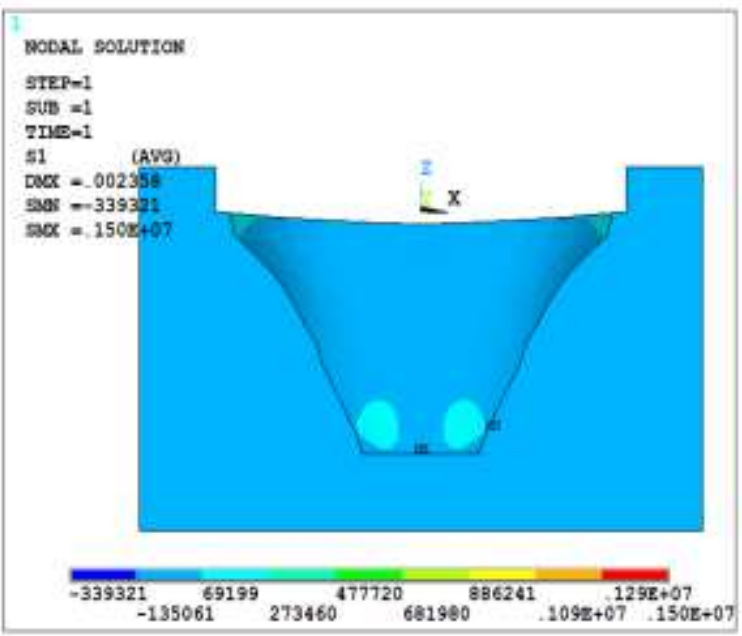

Figure 4. The first principal stress cloud map of arch dam under case $2(\mathrm{~Pa})$

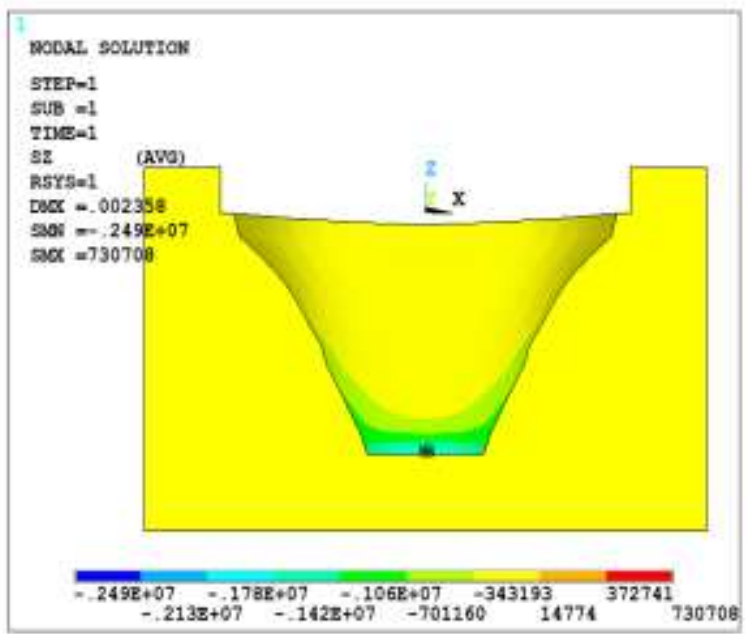

Figure 5. The vertical stress cloud map of arch dam under case 2( $\mathrm{Pa})$

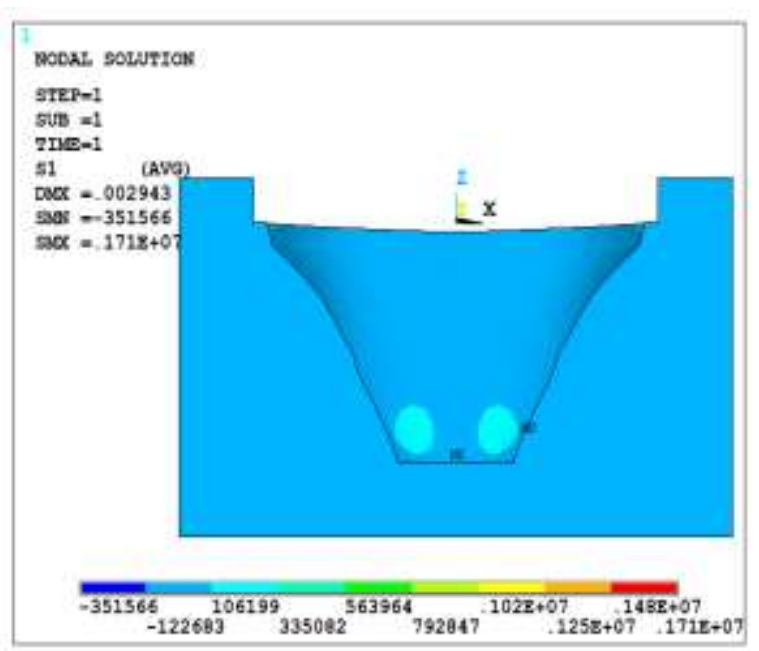

Figure 6. The first principal stress cloud map of arch dam under case $3(\mathrm{~Pa})$

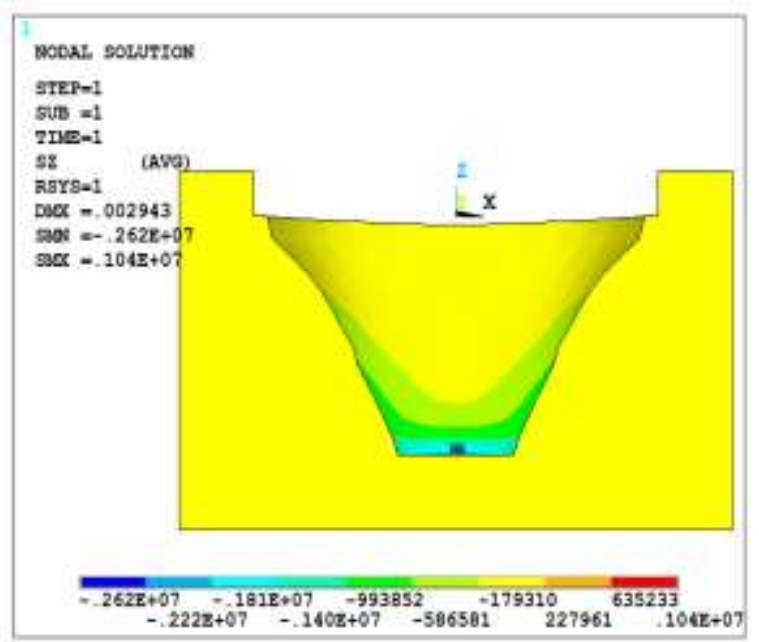

Figure 7. The vertical stress cloud map of arch dam under case $3(\mathrm{~Pa})$ 


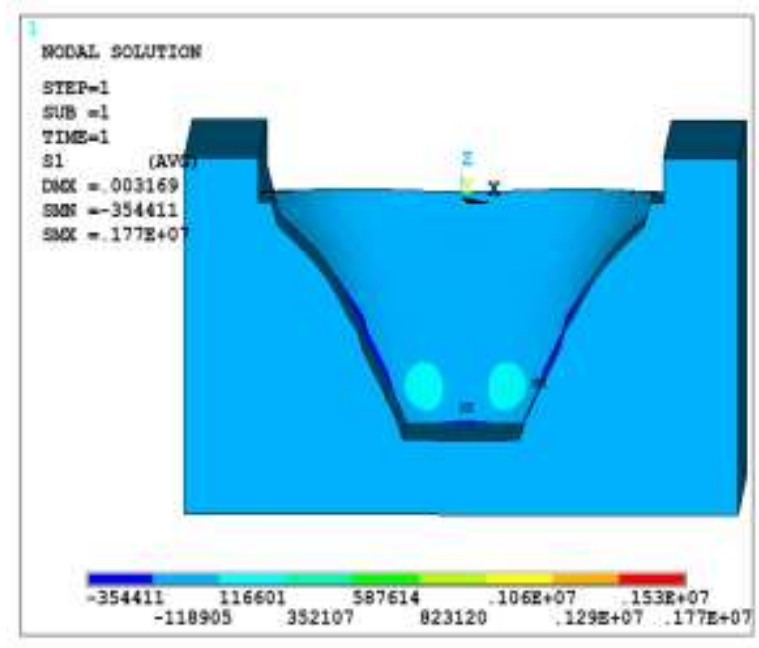

Figure 8. The first principal stress cloud map of arch dam under case $4(\mathrm{~Pa})$

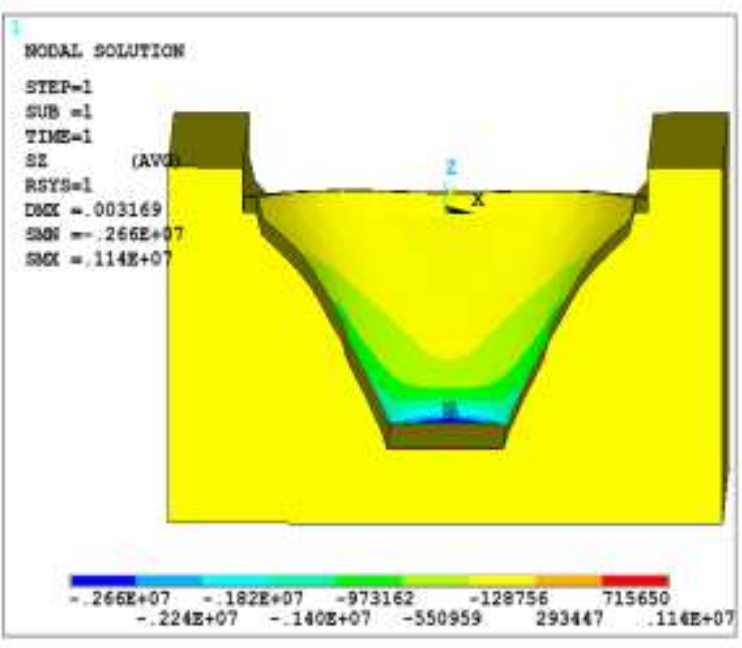

Figure 9. The vertical stress cloud map of arch dam under case 4（Pa）

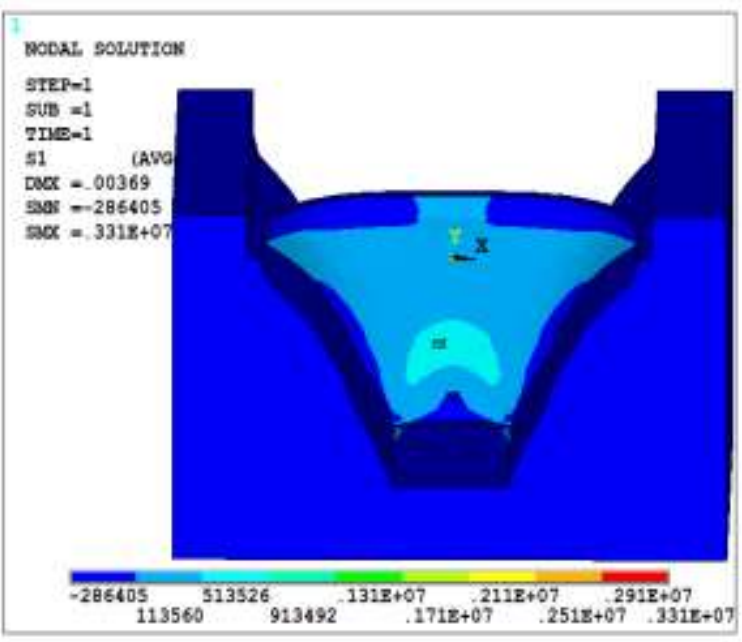

Figure 10. The first principal stress cloud map of arch dam under case $5(\mathrm{~Pa})$

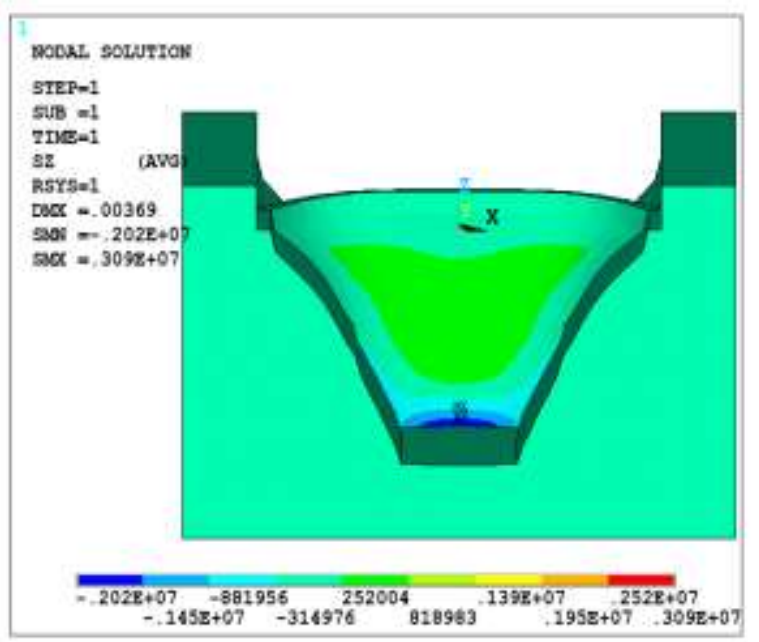

Figure 11. The vertical stress cloud map of arch dam under case $5(\mathrm{~Pa})$

It can be seen from Fig. 2 to Fig.11, under the role of water pressure and weight, the first principle stress and maximum vertical stress of arch dam are present in the junction of bedrock and the bottom of arch. Under case 5, due to the effect of Earthquake, the maximum first principle stress value of the arch dam is $3.31 \mathrm{MPa}$, the maximum vertical stress is $3.09 \mathrm{MPa}$. They both are present in the junction of the bottom of the dam upstream face and the foundation, but it only appears in very few areas, which belongs to the local stress concentration and there is no significant impact on the overall performance of the dam[10].

\section{B Deformation Analysis.}

The total displacement figures of concrete arch dam under each working condition are shown in Fig.12 to Fig.15.

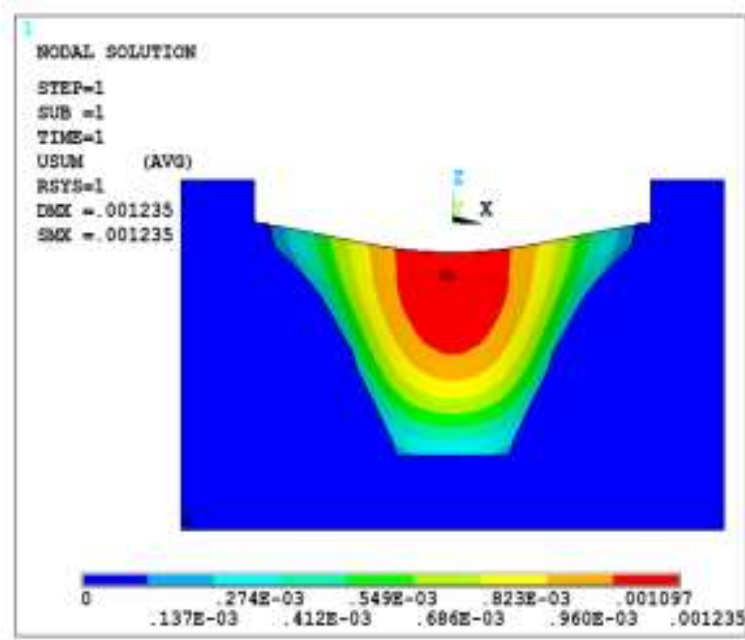

Figure 12. The total displacement cloud map of arch dam under case $1(\mathrm{~Pa})$ 


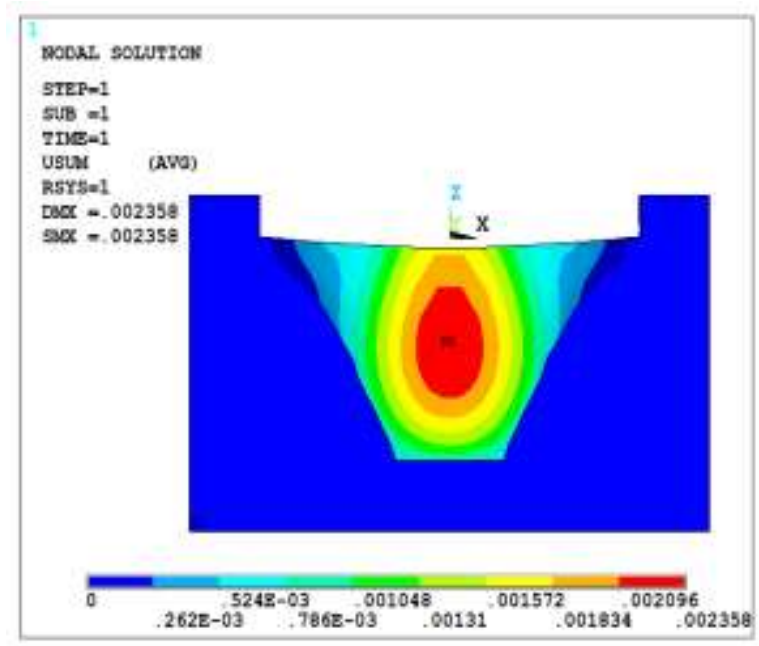

Figure 13. The total displacement cloud map of arch dam under case $2(\mathrm{~Pa})$

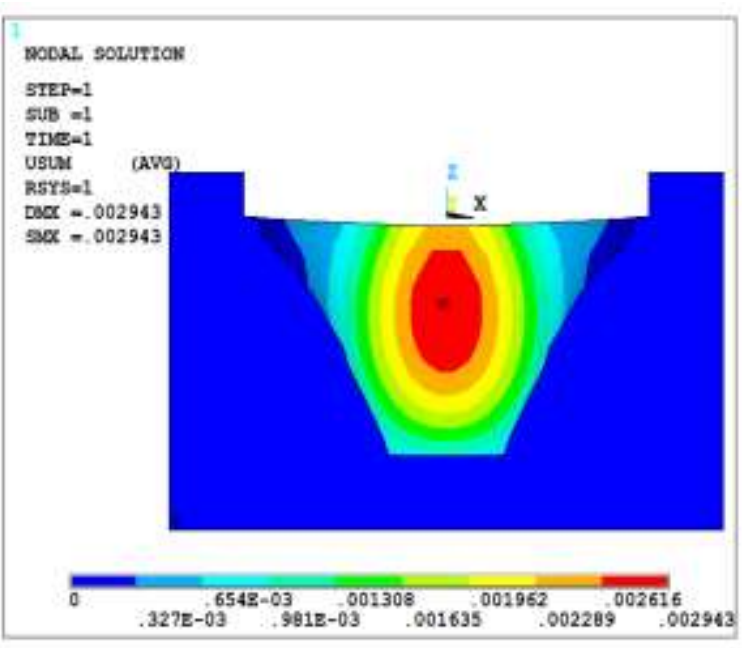

Figure 14. The total displacement cloud map of arch dam under case $3(\mathrm{~Pa})$

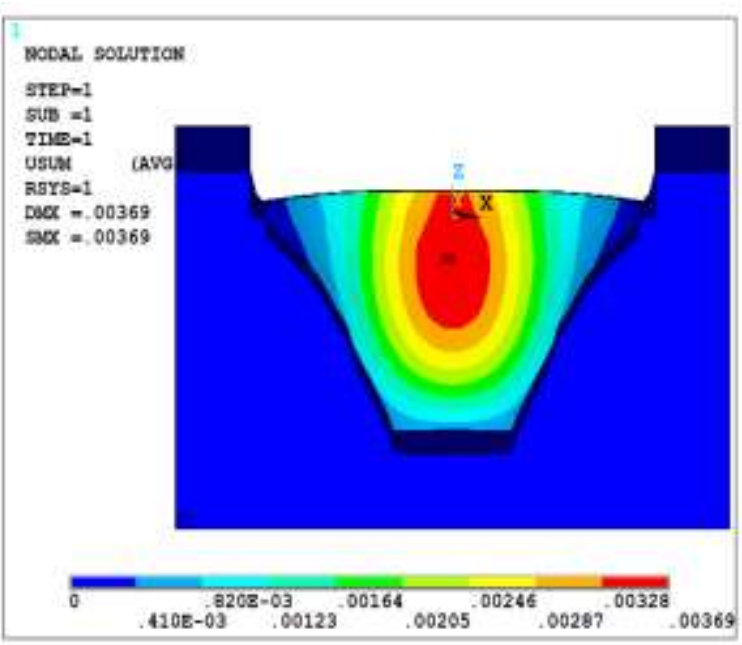

Figure 15. The total displacement cloud map of arch dam under case $5(\mathrm{~Pa})$
It can be seen from Fig.12 to Fig.15, under its own weight, the radial displacements of the arch almost present layered distribution and the maximum radial displacement occurs at the crest of the dam. Under the combined effect of water pressure and weight, the maximum radial displacement occurs in the central arch of the arch crown, the radial displacement was small at the junction of abutment and bedrock.

\section{CONCLUSION}

In summary, the Songbaishan reservoir using concrete arch dam scheme is reasonable. The first principal stress values of the arch was small, it can meet the strength requirements, the structural was safety and reliability. The deformation values of the dam was small, it can meet the stiffness requirements.

\section{REFERENCE}

[1] Bans Sevim,Ahmet Can Altunisik,Alemdar Bayraktar et al Estimation of Elasticity Modulus of a Prototype Arch Dam Using Experiments" Methods [J]. Journal of Materials in Civil Engineering,2012,24(4):321-329.

[2] Bans Sevim,Ahmet Can A!tunisik,Alemdar Bayraktar et al. Earthquake Behavior of Berke Arch Dam Using Ambient Vibration Test Results [J]. Journal of Performance of Constructed Facilities, 2012,26(6):780-792

[3] Sevim, B.,Bayraktar, A.,Altuni?ik, A.C. et al. Determination of water level effects on the dynamic characteristics of a prototype arch dam model using ambient vibration testing $[\mathrm{J}]$. Experimental Techniques,2012,36(1):72-82

[4] Li Shouyi,Ding Lujun,Zhao Lijuan et al. Optimization design of arch dam shape with modified complex method [J]. Advances in Engineering Software,2009,40(9):804-808

[5] SL191-2008. Design Code for Hydraulic Concrete Structure[S] China Water Conservancy and Hydropower Press, 2008.

[6] Mingrong Shen, Jianfeng Chen. Rock mechanics [M]. Tongji University Press, 2006.

[7] Xucheng Wang. Finite Element Method [M]. Tsinghua University Press, 2003

[8] Seyed Mohammad Seyedpoor,Javad Salajegheh,Eysa Salajegheh et al. Shape optimal design of materially nonlinear arch dams including dam-water-foundation rock interaction using an improved PSO algorithm [J]. Optimization and engineering,2012,13(1):79-100.

[9] SL282-2003. Design Code for Concrete Arch Dam [S]. China Water Conservancy and Hydropower Press, 2003.

[10] Bofang Zhu, Jizhang Gao, Zuyu Chen, Yisheng Li. Arch Dam Design and Research [M]. China Water Conservancy and Hydropower Press, 2002. 